\title{
ENTRE MEMÓRIAS E HISTÓRIAS: A LITERATURA INFANTOJUVENIL DE ONDJAKI ${ }^{1}$
}

Demétrio Alves Paz (UFFS)

Camila Knebel Fenner (UFFS)

Resumo: $O$ presente artigo tem por objetivo analisar as narrativas infantojuvenis do escritor angolano Ondjaki. Buscamos nelas algumas características específicas do autor e da cultura de seu país, num resgate da tradição oral ao rescrever e recriar histórias da cultura angolana. A literatura infantil de Ondjaki, assim como a de outros autores do período pós-colonial, é uma literatura de resistência, numa luta por espaço, pela valorização da cultura e pela construção da identidade de um país por muito tempo silenciado.

Palavras-chave: Oralidade; Literatura Infantojuvenil; Angola; Cultura; Ondjaki.

Abstract: The purpose of this essay is to analyze the children narratives by the angolan writer Ondjaki. We seek in them some specifics characteristics of the author and the culture of his country, in a recovery of oral tradition by rewriting and recreate histories of Angolan folklore. Ondjaki's children literature, as well as many other post-colonial writers, is a resistant literature in a fight for space, for valorization of a culture and for the construction of an identity in a long time unvoiced country. Keywords: Orality; Children Literature; Angola; Culture; Ondjaki.

\section{INTRODUÇÃO}

A literatura infantil de Ondjaki transita em meio a memórias e histórias do cenário angolano. Ao debater temas importantes, o autor utiliza uma linguagem poética, composta por elementos da oralidade, valorizando a cultura de seu país. Dessa forma, entendemos que o escritor elabora

1 Título em inglês: "Between memories and histories: Ondjaki's children literature". 
uma escrita emancipatória, isto é, aquela que suscita uma vontade de libertação não só do passado colonial como também de uma afirmação da autonomia literária angolana (TUTIKIAN, 2009).

Ndalu de Almeida nasceu em Luanda, em 1977 e adotou o pseudônimo de Ondjaki. Estudou em Lisboa, formando-se em Sociologia, em 2002. Iniciou sua carreira literária com o livro de poesia Actu Sanguíneo (2000), a partir daí já teve vários outros títulos publicados em diferentes gêneros: poesia, conto, romance, novela, dramaturgia e documentário para cinema.

Os livros analisados neste ensaio são: O leão e o coelho saltitão (2009), Ynari, a menina das cinco tranças (2010), O voo do golfinho (2012), Ombela, a origem das chuvas (2015), A bicicleta que tinha bigodes (2015) e $O$ convidador de pirilampos (2018). Todos eles têm pontos em comum: recuperam as memórias de um povo que foi por muitos anos silenciado por seus colonizadores. De acordo com Michael Pollak,

[a]o privilegiar a análise dos excluídos, dos marginalizados e das minorias, a história oral ressaltou a importância de memórias subterrâneas que, como parte integrante das culturas minoritárias e dominadas, se opõem a "Memória oficial", no caso a memória nacional. $(1989$, p.4) 
Uma escrita emancipatória surge com força após a guerra civil (que se instaurou no país entre 1975 e 2002) iniciada logo depois da independência de Angola em 1975. Um dos propósitos dessa produção é a reescrita de marcas da tradição angolana não valorizadas pela "memória oficial", isto é, não legitimadas pelo colonizador. A literatura infantil possui, entre outros elementos, "o de ensinar e educar recreando, o de moldar espíritos através da atividade lúdica; e ainda outro aspecto, a superação do real através do mítico, num jogo que a criança entende e aceita" (GUERRA, 1980, p.12). Como veremos a seguir, vários escritores assumem essa tarefa a partir da independência.

\section{LITERATURA INFANTIL ANGOLANA: UMA ESCRITA EMANCIPATÓRIA}

Em Angola, tanto após a proclamação da independência em 1975 quanto o término dos conflitos civis em 2002, os escritores passaram a trabalhar em um movimento de recuperação das tradições do país. Tradição antes ocultada pela cultura do colonizador, que estabeleceu suas crenças e costumes no território africano, em um processo de assimilação no qual ocorreu a sobreposição cultural portuguesa sobre a africana (MACEDO; CHAVES, 2007).

Em virtude da marginalidade e da marginalização da literatura de angola durante todo o colonialismo português, 
surgiram, após a independência, entidades determinadas a incentivar os escritores nacionais a resgatar as histórias do folclore de seu povo e a começar a reconstruir a identidade dos colonizados. Dentre elas, destacamos $\mathrm{O}$ Instituto Nacional do Livro e do Disco (INALD), o Jornal de Angola e a União dos Escritores Angolanos (UEA), que divulgaram a cultura a um novo público por meio de publicação de livros, discos e artigos para a recente nação.

A partir desse novo momento histórico, deu-se voz lou melhor, espaço para publicar) a muitos escritores que tinham o objetivo comum de valorizar a cultura nacional. A estratégia utilizada foi a de pensar em uma literatura que contasse a história do país, incluindo os conflitos, sem silenciar a tradição, a um público que constituiria essa nova Angola livre de guerras. Dessa forma, "os autores angolanos tomaram a si a tarefa de (re)contar essas narrativas, como forma de fazer presente o que, por tanto tempo, o colonialismo tentara abafar, ao mesmo tempo em que ensinavam às novas gerações os caminhos da tradição" (MACEDO; CHAVES, 2007, p.156). Assim, intensificou-se a produção de literatura infantil no país.

A percepção da importância da literatura para jovens leitores é um grande passo para a formação de novos 
leitores, pois resulta em benefícios para o país já que "por iniciar o indivíduo no universo literário, a literatura infantil deve ser utilizada como um instrumento para a sensibilização da consciência, para a expansão da capacidade e interesse de analisar o mundo" (SANTANA, 2007, p.95). Na obra de Ondjaki, a literatura popular é resgatada na forma de vivências da infância, assim como as memórias da guerra são sutilmente retratadas. Parte da realidade social se mistura com temas já conhecidos há muito tempo na tradição oral, tais como: mitos, lendas, fábulas em que a sabedoria vence a força e ocorre a realização de "diálogos da modernidade com a tradição ancestral" (FONSECA, 2008, p.76). Todos esses elementos aparecem na escrita do autor, que apresenta um grande retrato de Angola, de seu povo, de suas crenças e de suas tradições.

\section{ELEMENTOS CONSTANTES NA ESCRITA DE ONDJAKI}

Com relação à tradição africana, Hampâté Bâ nos diz que:

Nunca se deve generalizar. Não há uma África, não há um homem africano, não há uma tradição africana válida para todas as regiões e todas as etnias. Claro, existem grandes constantes (a presença do sagrado em todas as coisas, a relação entre os mundos visível e invisível e entre os vivos e os mortos, o sentido comunitário, o respeito religioso pela mãe etc). (2013, p.12) 
Portanto, procuramos identificar, na escrita de Ondjaki, alguns desses elementos constantes. Uma característica marcante na literatura infantil do autor é a presença da oratura. Segundo Fonseca "o termo oratura aponta o diálogo, nem sempre harmônico, entre formas expressivas ligadas à tradição oral e à escrita. Engloba (no francês, oraliture) a simultaneidade: oralidade e escrita, vazada em duplo movimento" (2008, p.63). Ou seja, é na retomada de determinados mitos e lendas, ou até mesmo formas de contar uma estória pela escrita que o autor utiliza a oratura.

Nas literaturas africanas em geral e nas de língua portuguesa em particular, tal como nos textos de Luandino Vieira, Boaventura Cardoso, Manuel Rui e, no nosso caso, Ondjaki, ocorre a incorporação de

[r]ecursos que remetem aos modos de narrar dos contadores orais e ao fascínio e encantamento que os eventos narrados exercem sobre os que ouvem. No caso específico de escritores provenientes de culturas de forte herança oral, [...], é instigante pensar em práticas literárias que se revelam nas diferentes formas com que o escritor assume os bens culturais herdados da oralidade. (FONSECA, 2015, p.125)

Esse movimento duplo, ou melhor, o diálogo entre oralidade e escrita, é muito presente nos livros de Ondjaki. O primeiro exemplo disso encontra-se na obra $O$ Leão e o 
Coelho Saltitão (2009), enquadrada em uma das seis classes principais de manifestações culturais orais angolanas: MiSoss, pois "Nos misossos, os animais, assim como os homens, revestem-se de dignidade própria e são dotados do dom da fala" (MACEDO; CHAVES, 2007, p.20). É o que acontece com os animais do livro da coleção Mama África, a história contada por Ondjaki fala sobre uma trapaça planejada pelo Coelho Saltitão e o Leão. O grande problema da narrativa é a fome causada por inundações e incêndios na Floresta Grande, isso leva os personagens a procurarem saídas inusitadas, tais como: a armação do funeral do cão morto do Coelho e a "parceria" entre ele e o Leão. São características principais nos personagens a esperteza do Coelho e a falta de malícia do Leão, o que é comum nesse tipo de história, "pode-se verificar que grande parte dos misossos acaba por enaltecer a astúcia, em detrimento da força bruta" (MACEDO; CHAVES, 2007, p.20).

No livro, Ondjaki reescreve a "Estória do Coelho e Leão" relatada por David Yava Mwau, parte do livro Viximo (1987), contos da oratura Luvale, de José Samuila Cacueji. Na apropriação do texto Luvale, pelo escritor angolano, notamos que "a relação com as tradições orais e com a oralidade é, de início, uma relação em "segunda mão", resultante, em grande parte, dos casos, não de uma experiência vivida, mas 
filtrada, apreendida, estudada." (LEITE, 2012, p.32-33). Dessa forma, o novo texto herda da literatura tradicional

a função de ensinar, aconselhar e até mesmo convencer, desenvolvendo uma visão maniqueísta (o bem premiado e o mal castigado) da disputa entre fortes e fracos, do bem e do mal, e o mais fraco acaba sempre por vencer - às vezes pela astúcia; a ganância, a soberba, caem por terra e são vencidas. (DEBUS, 2013, p.1139)

Percebemos a oratura não somente pela estória, mas também pelo modo como ela é escrita. $O$ autor escreve para o público-leitor de maneira que ela parece ser contada oralmente. O início do livro, "Há muitos, muitos anos, na Floresta Grande houve um grande problema" (ONDJAKI, 2009, p.5) e o final "foi assim que aconteceu" (2009, p.37), indicam esse traço de oralidade.

O livro Ynari, a menina das cinco tranças (2010), termina da mesma maneira. A história dedicada a todas as crianças do mundo e a todas do país de nascença do autor, Angola, começa com "Era uma vez" e conta a aventura de Ynari, a menina das cinco tranças. Ela mora em uma aldeia e certo dia perto do rio encontra um homem pequenino com quem começa a conversar sobre o significado das palavras. Ele Ihe pergunta sobre suas cinco tranças e Ynari conta a esse homem pequenino que já nasceu com elas e que, segundo 
sua vó, um dia ela descobriria o porquê disso. Cada trança tem um propósito, o homem pequenino acaba ajudando Ynari a descobrir quais são eles.

O homem pequeno e mágico e Ynari vão para a aldeia dele e encontram o velho muito velho que inventa palavras e a velha muito velha que destrói palavras. Essa chegada na aldeia dos homens pequenos é descrita com bastante detalhes, assim como o ritual pelo qual Ynari passa para descobrir a sua magia. Como Fonseca destaca, "esses rituais insistem na importância que os idosos têm em comunidades africanas que conservam hábitos característicos do uso da palavra com função mágica" (2008, p.76).

Durante o ritual, ela recebe a palavra PERMUTA, que tem relação com o seu poder e descobre qual é sua magia. Ela e o homem pequeno e mágico passam de aldeia em aldeia para realizar a permuta entre a palavra que cada povo queria conhecer e uma das tranças de Ynari. Foi assim em cinco aldeias que estavam em guerra, até Ynari passar a se chamar "a menina sem tranças" e poder pedir a velha muito velha que destrói palavras para destruir a palavra "guerra". No livro,

a fala pode criar a paz, assim como pode destrui-la. É como fogo. Uma única palavra imprudente pode desencadear uma guerra, do mesmo modo que um graveto em chamas pode provocar um grande incêndio. [...] A 
fala, por excelência, é o grande agente ativo da magia africana. (BÂ, 2010, p.173)

E a história de Ynari é uma grande representação disso, pois a palavra serve como uma ferramenta transformadora dentro da história. Nela, todas as situações são resolvidas por meio do diálogo.

Em O voo do golfinho (2012), ao contrário das duas obras anteriores, não há referência à guerra, deixando clara a mensagem de otimismo, ao dizer que todos podem aprender a ser o que quiserem, assim como o golfinho aprendeu a ser pássaro e se juntou ao "Bando da LIBERDADE" (ONDJAKI, 2012, p.21). O livro retoma a ideia de emancipação de um povo que anseia por liberdade e incentiva as gerações futuras a defender sua identidade.

Especificamente nessa obra, devido ao público destinatário: crianças recém alfabetizadas, há uma certa ingenuidade, porque existe a oportunidade de a personagem ser o que quiser, mas não há impedimento algum a essa vontade. Percebemos, com essa narrativa, que "a literatura infantil tem uma importante tarefa, não mostrar apenas aquilo que foi negado a seu povo, mas maneiras de construir e espremer sonhos" (DEVIDES, 2014, p.301). Dessa forma, o texto literário adquire a função de incentivar e dar 
esperança aos filhos daqueles que conheceram e sofreram as consequências de uma guerra e de uma realidade bastante desigual.

Em Ombela, a origem das chuvas (2015b), temos novamente o resgate do folclore, que, de acordo com Oscar Ribas, "representa o esteio, a estrutura, a fonte da história de um povo" (1964, p.31). O livro inicia com a frase "dizem os mais-velhos que a chuva nasceu da lágrima de Ombela, uma deusa que estava triste" (ONDJAKI, 2015b, p.7). Ondjaki retoma a oratura, trazendo expressões como "dizem que", e a importância da fala dos mais-velhos. De acordo com Fonseca,

nessas sociedades, o homem é sempre significado pelo que aprendeu com os mais velhos, e esse aprendizado é naturalmente passado aos que vêm depois dele, como forma de garantir a coesão do grupo. Do mesmo modo, o culto à palavra dos antepassados encarna-se no culto ao mais velho, que é respeitado em virtude do saber que detém. (2008, p.79)

Além de trabalhar com mitos e lendas, o escritor angolano assume a voz infantil dentro de algumas obras e faz com que o leitor sinta na mesma intensidade que as personagens. É o caso do livro A bicicleta que tinha bigodes (2015a), em que um narrador autodiegético, um menino angolano, decide 
participar de um concurso de histórias para ganhar uma bicicleta. Contudo, ele acaba falando sobre o que ocorre com as demais crianças que vivem naquela rua de Luanda. Temos aqui um microcosmo (a rua) representando o macrocosmo (o país).

Ao detalhar as dificuldades da população como: a falta de luz, a falta de água, a pobreza denunciada no "sumo aguado", os adultos poupando comida para as crianças, como no "matabicho" (café da manhã) preparado pela Avó Dezenove, o narrador desperta no leitor a empatia ao se imaginar na narrativa, visto que representa o ponto de vista infantil. Ondjaki faz isso de uma maneira muito delicada, principalmente em trechos como o seguinte:

O matabicho ia aparecendo, devagar, para parecer que tinha muita coisa. A minha Avó com os teatros dela: bocados de pão, depois a manteiga, leite aguado já misturado assim na cozinha para eu não ver, um bocadinho de café que eu sempre pedia.

- Avó, tu não tomas leite?

- Só café.

Era mentira de poupar as coisas para as crianças, pois quando havia mais de um pacote a Avó também matabichava leite. (2015a, p.40)

A infância feliz em Luanda, ainda que não abastada, aparece no cotidiano das personagens por meio das 
brincadeiras, da imaginação e do sonho do personagem principal em ganhar uma bicicleta colorida no concurso da Rádio Nacional. O menino acredita que ganhará a bicicleta utilizando uma história do Tio Rui. Ele é um escritor da rua, caracterizado pelos enormes bigodes e a voz anasalada, por isso as crianças inventaram que ela se dá por meio das palavras que sobram em seu bigode, tal como diz Isaura:

- Não vês como são os bigodes do tio Rui?

- São como?

- São assim tipo capim que já não se corta desde o último cacimbo.

- E depois?

- Depois que alguns sons e algumas palavras ficam presas no bigode. Então só ouvimos já o resto. (ONDJAKI, 2015a, p.14)

Na primeira orelha da obra, Ondjaki (2015a) ressalta que "não há como fugir ao que tem de ser dito: escrevemos em busca da voz que mais nos fala por dentro, ajustando a vida (a escrita?) às 'falas do lugar'. Escrevendo para relembrar o que ainda não tinha sido contado...". Assim, a ideia de dar voz à história do povo angolano, de valorizar a realidade vivida por ele e representá-la em seus aspectos positivos e negativos fica evidente.

Elemento recorrente na tradição africana, a valorização da fala dos mais velhos, aparece também na escrita do livro. 
O personagem principal, assim como todas as crianças da história, possui um enorme respeito pela palavra dos mais velhos durante a narrativa. O menino, neto da Avó Dezenove, por exemplo, não deixa de obedecer e crer em seus conselhos como se seus ditos fossem sagrados.

O menino, enfim, escreve sua carta para a Rádio Nacional de Angola, não contando uma história, tal como proposto pelo concurso. Ele faz um pedido ao "Camarada Presidente da República Popular de Angola" para que sejam distribuídas "prendas" para todas as crianças de Angola. Além de pedir para que não falte tanta luz nem tanta água na rua em que moram. Ao invés de criar uma história, o narrador opta por "mostrar" a realidade ao presidente. Com isso, ele demonstra empatia com o povo angolano, assim como ilustra o ideal de bem-estar social para todos ao solicitar infraestrutura básica.

No último livro analisado, O convidador de Pirilampos (2018), o narrador assume a posição de um menino. Ele mora com seu avô, seu companheiro para passeios na Floresta Grande. O menino tinha um fascínio por pirilampos de tal modo que inventou um apanhador de pirilampos para tentar comunicar-se com eles e "cientistar". Por meio dos pirilampos, o narrador representa o processo de contação de histórias, em que os mais velhos transmitem aos mais 
jovens a sabedoria ancestral. Esse respeito aparece já na diferenciação dos animais, existem os pirilampos cintilantes e "os apagados são os mais sábios. Também conhecidos como pirivelhos" (ONDJAKI, 2018, p.7). Eles possuem a mesma função dos ancestrais africanos, que é a de passar o conhecimento pela tradição oral:

- Vocês são os pirilampos cintilantes. E como se chamam os outros?

- São os pirivelhos. Aqueles que não devem ser encontrados.

- Por que não?

- Porque eles são os contadores das estórias muito, muito antigas.

(ONDJAKI, 2018, p.40-41)

Em função das invenções do menino, ele consegue capturar os pirilampos cintilantes. Ao perceber que estava preso, um dos animais fala: "isto afinal é um apanhador de pirilampos... Mais espertos foram os mais-velhos que fecharam os olhos antes de olharem todos os brilhos e todas as cores. E agora?" (ONDJAKI, 2018, p.21). O avô aconselha o neto a soltar os pirilampos, pois a gaiola que ele construiu não era a casa deles. Consequentemente, os pirilampos ficariam tristes. Foi isso que aconteceu e o pirilampo Edson, nome dado pelo menino, pede para ser libertado junto com os demais, pois precisam de sua casa e de suas histórias: 
- Eu também posso contar estórias...

Tentou o menino.

- Podes, mas as estórias da nossa gente vão se perder para sempre. $E$ as estórias não são de ninguém. São da floresta grande. São do tempo. (ONDJAKI, 2018, p.52)

O menino, mesmo triste, solta os pirilampos e promete deixar o convidador de pirilampos na Floresta Grande para que eles sempre possam admirar as luzes coloridas que o convidador gera. Além disso, o pirilampo expressa a necessidade de preservação das histórias de seu povo. 0 menino, mesmo sendo capaz de contar histórias, não contaria as dos pirilampos, numa alegoria do processo colonial em que a cultura portuguesa (estrangeira) foi imposta. O livro termina com a continuidade do ciclo de contação de histórias por meio dos pirilampos:

Hoje, passados tantos anos, Edison também já é um pirivelho. Quando há Lua Nova, os pirilampos cintilantes sabem que o podem encontrar sentado no velho convidador de pirilampos, contando uma estória sua. Uma estória antiga. E que começa assim:

Perto da nossa Floresta Grande havia uma casa, onde vivia um menino e o seu avô e o seu canivete e as suas laranjas. Era um menino muito curioso, que cientistava pirilampos. E que aprendeu a ser amigo do escuro. (ONDJAKI, 2018, p.58-59) 
Assim, temos, por meio dos pirilampos, a representação do processo de contação de histórias em que os mais velhos (os mestres das palavras) são os responsáveis pela transmissão de ensinamentos aos mais jovens para que um dia eles também passem adiante o que ouviram.

\section{CONSIDERAÇÕES FINAIS}

A partir da leitura das obras aqui analisadas, percebemos um diálogo entre gerações, a luta pelo reconhecimento, tão merecido, da cultura de um país, bem como a importância da literatura infantil na reescrita da história recente. A obra infantojuvenil de Ondjaki realiza a importante tarefa de sensibilizar o leitor, colocá-lo diante da perspectiva do povo angolano, emancipando-a da visão colonial, chegando ao que Francisco Salinas Portugal chama de "reelaborações culturais de um passado concreto, de uma forma de ser e estar no mundo" (1999, p.36).

Para além da dimensão oral do texto, há o humanismo presente fortemente nas histórias. A carga sentimental, principalmente na interação entre jovens e velhos por meio do aprendizado pela escuta, é o que faz os textos de Ondjaki serem lidos e relidos por novos e experientes leitores. Em suas obras, histórias populares são resgatadas e eternizadas, por meio da escrita, dentro do grande tempo, mantendo a 
tradição viva. O autor dá sequência a essa tradição, passando para os leitores parte do folclore de seu país, recontando histórias da tradição oral, fortificando o movimento de representação de Angola na literatura para jovens leitores.

\section{REFERÊNCIAS}

BÂ, Amadou Hampâté (2010). "A tradição viva”. In: KI-ZERBO, Joseph (Ed.). História Geral da África 1: Metodologia e pré-história da África. Brasília: UNESCO.

(2013). Amkoullel, o menino fula. São Paulo: Palas Athena.

CACUEJI, José Samuila (1987). Viximo: contos da oratura Luvale. Lisboa: Edições 70.

DEBUS, Eliane Santana Dias (2013). "A Literatura Angolana para Infância". Revista Educação \& Realidade, Porto Alegre, 38(4), Out./Dez.

DEVIDES, Michelle Mittelstedt (2014). "Evidências de discurso de resistência na literatura infantil de Ondjaki: uma análise da obra Ynari, a menina de cinco tranças". Revista de Humanidades, Tecnologia e Cultura. Faculdade de Tecnologia de Bauru, 4.

FONSECA, Maria Nazareth Soares (2008). Mia Couto: espaços ficcionais. Belo Horizonte: Autêntica Editora.

(2015). Literaturas africanas de Língua Portuguesa: mobilidades e trânsitos diaspóricos. Belo Horizonte: Nandyala.

GUERRA, Henrique (1980). Três histórias populares. Lisboa: Edições 70. MACEDO, Tania; CHAVES, Rita (2007). Literaturas de Língua Portuguesa: Marcos e marcas - Angola. São Paulo: Arte \& Ciência.

ONDJAKI (2009). O leão e o coelho saltitão. Rio de Janeiro: Língua Geral. (2010). Ynari: a menina das cinco tranças. São Paulo: Companhia das Letrinhas.

(2012). O voo do golfinho. São Paulo: Companhia das Letrinhas. (2015a). A bicicleta que tinha bigodes. Rio de Janeiro: Pallas. 
(2015b). Ombela: a origem das chuvas. Rio de Janeiro: Pallas míni. (2018). O convidador de pirilampos: estórias sem luz elétrica. Rio de Janeiro: Pallas.

POLLAK, Michael (1989). Memória, Esquecimento, Silêncio. Estudos Históricos. Rio de Janeiro, 2(3).

PORTUGAL, Francisco Salinas (1999). Entre Próspero e Caliban: literaturas africanas de língua portuguesa. Laiovento: Santiago de Compostela.

RIBAS, Oscar (1964). Missosso: Literatura Tradicional Angolana Volume III. Luanda: Tipografia Angolana.

SANTANA, Heloíse Cabral (2007). "Análise das palavras em Ynari: a menina das cinco tranças". In: SECCO, Carmen Lucia Tindó. Entre fábulas e alegorias: ensaios sobre literatura infantil de Angola e Moçambique. Rio de Janeiro: Quartet.

TUTIKIAN, Jane (2009). "Lá onde mora a infância (um estudo dos contos de Luandino Vieira e de Ondjaki)". In: REMÉDIOS, Maria Luiza Ritzel; SILVEIRA, Regina da Costa da. Redes \& Capulanas: identidade, cultura e história nas literaturas lusófonas. Porto Alegre: UniRitter.

Demétrio Alves Paz é Doutor em Letras (PUCRS), professor Associado de Teoria Literária e Literaturas de Língua Portuguesa na Universidade Federal da Fronteira Sul (UFFS), Cerro Largo - RS, Coordenador do projeto de pesquisa "A contística de Ondjaki", com bolsa de IC do CNPq. Possui artigos publicados nas revistas Abril, Via Atlântica, Nau Literária, Terra Roxa e outras terras, Boitatá, entre outras, versando principalmente sobre literaturas africanas e ensino de literatura.

ORCID iD: http://orcid.org/0000-0002-5305-290X

Camila Knebel Fenner é Graduanda em Letras na UFFS e aluna voluntária no projeto de pesquisa "A contística de Ondjaki". 